By T. D. MORRIS

\title{
Techniques of Appraising the Administrative Strength of an Organization'
}

Mr. Morris is a member of the firm of Cresap, McCormick and Paget, management engineers, which surveyed the operations of the Acquisitions Division, of the New York Public Library Reference Department.

$\mathrm{M}^{\circ}$ OST OF us in our own special field of endeavor are preoccupied with the professional or technical content of our work. That is to say, we are essentially craftsmen in our approach to and performance of our tasks. I have recently seen a vivid illustration of this fact in an industrial plant which overhauls and repairs ships. With but few exceptions the jobs done aboard a ship are highly specializedthe disassembly, repair and reinstallation of engines, valves and pumps; the installation of electrical and communication devices, etc. The quality of the product produced in this plant was superior. The machines and equipment of the vessels repaired functioned to perfection after the craftsmen finished their work. But the management of the plant was not satisfied because the cost of this excellent performance exceeded that of its competition. A management survey revealed the reasons for the high cost performance: the plant lacked a degree of administrative management commensurate with its high standards of professional

1 Revision of a paper presented at the meeting of the Acquisition Department Heads of Research Libraries Round Table, AL.A Conference, January 30, 1951, Chicago. management. As a consequence, cost controls were neglected as evidenced by the following conditions: ( 1 ) There were too many people. The supervisors were aware of this, but justified the situation on the grounds that it guaranteed high quality work. By having an excess of talent available, no job was subjected to inferior workmanship. But because no one in management had determined precisely how many people were actually needed on a year-round basis, there was a wasteful surplus rather than an intelligent reserve of man power. (2) Excessive staffing led to high costs due to idle time and to the failure to conserve and utilize fully the talent of skilled employees, (3) Service to the customer was actually reduced because the number of days required to repair the ship and return it to its operator was greater than necessary if the work had been carefully planned and scheduled in advance, and (4) There was a disregard of materials utilization in this plant just as there was of the utilization of skilled man power.

This example illustrates in an extreme situation, the undesirable consequences which can occur when management does not counterbalance professional zeal with a strong emphasis on administrative competence.

\section{The Meaning of Administrative Com- petence}

Let us define the meaning and scope of 
administrative competence in an organization:

Administrative competence is that characteristic which causes management to seek the accomplishment of its primary technical or professional tasks in the most expeditious and economical manner consistent with quality workmanship, but without stifling initiative or overburdening its skilled man power.

The techniques of competent administrators are threefold:

I. Sound organization of personnel. This technique places each person in a job that makes the most continuous use of his highest skills, which compensates each person equitably, and which places in positions of authority those who will receive the best response from their subordinates and their superiors.

2. Simple procedures. This technique has as its purpose the conservation of time and energy of professional personnel in the paper work phases of an activity, and the provision of accurate and useful records and communications.

3. Effective controls. This technique seeks out the most direct means of obviating loss of time and waste of materials and of assuring expeditious processing of work in accordance with predetermined standards of quality.

The steps by which administrative strength can be added to an organization may be described by referring specifically to a library acquisition activity. Discussion of some of the techniques which were useful in a recent study of the New York Public Library's Acquisition Division may suggest ways and means of improving the administration in other libraries and of other library activities. Although these are the techniques of professional management engineers, they may well be explored by the individual administrator who cannot afford to employ professional surveyors.

\section{Testing the Soundness of the Organization}

Organizational analysis is the most difficult, but frequently the most productive, phase of an industrial management survey. To many the word organization implies a formidable chart composed of boxes, authority lines, echelons of responsibility and job titles - often artificial, stilted, unrealistic, and designed to justify the prestige and compensation of certain staff members. Unfortunately, this tool of administration has been subject to just such misuse.

In the correct sense, organization planning is the development of specifications, setting out the performance which top management desires from a group of individuals assigned to a single major function. The organization plan, which is far more than a chart, starts with a precise delineation of the objectives of the group, the qualifications required of those who are appointed to carry out the objectives, the type and volume of the specific tasks to be performed, the number of positions to be established, and finally the manner in which the tasks are to be distributed among all positions from the most responsible to the most routine.

The evaluation of the organization of the NYPL Acquisition Division was accomplished through a series of four steps:

I. In Step $I$, the elements of the complete acquisition function of the Reference Department were defined. ${ }^{2}$ This definition revealed that the acquisition function involves almost every executive and department since it is one of the fundamental reasons for the existence of a reference library. It was thus necessary to examine carefully the relationships between the Acquisition Division and other divisions of the Reference Department. Immediately uncertainties with respect to the precise scope of the Acquisition Division's responsibilities were revealed. This led to Step 2 in testing the soundness of the organization.

2. In Step 2, all instances of potential

2 The survey described by Mr. Morris was limited to that part of the NYPL supported by endowed funds. The acquisition agency of the city-supported Circulation Department was not included, except incidentally, in the over-all study. 
overlap or duplication with other parts of the library were analyzed. It was found that the principal areas of potential overlap existed with the Preparation Division in connection with the recording of holdings, of annuals and nonperiodical serials, and with the various subject divisions in connection with recording and following-up receipt of current periodicals. The latter instance of overlap was found to involve considerable duplication of effort. A careful appraisal of the records required in each division was then made in order to reach a practical decision as to the most appropriate division of responsibilities. It is hoped that the result will secure more complete control over current periodicals with less cost in man power. These benefits, it should be noted, will result from a more logical organization rather than from changes in basic procedures.

3. Step 3 in the study of organization dealt with the assignment of duties, responsibilities and workload within the Acquisition Division itself. This step required a careful scrutiny of each position, first by a personal interview with each assistant, and secondly by asking each assistant to prepare a daily diary for one week of the duties performed and the time spent on each. These studies revealed the existence of problems which often develop in a large organization which performs a variety of tasks:

Key supervisors were so burdened with the performance of the immediate technical tasks of processing procurement requests that a minimum of time was available for reviewing the quality and cost of performance.

There were also instances in which senior assistants were performing a mixture of duties requiring distinctly different levels of skill. This condition militated against low costs and served to depress the responsibility level, and thus the earnings opportunity, of senior assistants.

The volume of work assigned to each desk was not equitable since some employees had only one to two days work ahead, while others had a work-load which was several weeks in arrears.

These findings led to a reevaluation of the basis for supervisory and work assignments and the resultant development of a new pattern of organization in which need for two types of supervision was recognized: that concerned primarily with the technical or professional aspects of procurement (such as, selecting sources, editing orders, etc.) and that concerned with administration, including the utilization of personnel, the distribution of work assignments and the expeditious performance of work. Further discrimination was proposed to specialize between procurement duties and receiving-distribution duties so as to minimize the mixing of distinctly different skill levels in the same position. Such revisions may be expected to achieve the highest use of the talents of all members of the staff.

4. Step 4 consisted of defining precisely the duties and responsibilities of each position showing ( $\mathrm{I}$ ) to whom the incumbent reports, (2) a statement of the objectives of the position, (3) a description of the principal duties performed, classified by procurement, receiving and distribution, and general administration, and (4) an enumeration of the subordinate positions supervised.

\section{Simplifying Procedures}

Organizational analysis is the foundation of a thorough-going industrial management study in any activity regardless of its size or the nature of its work, In fact, a comprehensive organization study requires as a prerequisite full knowledge of procedures, work methods and control techniques. Given this knowledge, work simplification becomes a matter of selecting for more in- 
tensive study those phases of the work which pose problems of high cost, inaccuracy, tardy processing, arrearages of work, etc. It was evident in this study that the acquisition staff at NYPL had been hard at work on the simplification of its major procedures for several years. As a consequence, the chief contributions of the survey included suggesting refinements and alternative solutions.

A few of the techniques which were used to guide thinking respecting revisions in forms, records and equipment may be noted :

I. Analyzing the Condition of Nonperiodical Serial Records

The immediate problems which attracted attention at New York were; a serial record file so congested by the presence of inactive and inaccurate records that reference was made tedious and costly; and a sense of despair among serial assistants who could see no practical means of accomplishing a complete revision of the serial records within a reasonable period of time. A random sample of about three per cent of the 200,000 cards in file provided a useful and reasonably reliable picture of the problem and confirmed the wide-spread belief that over half of the records in the file were dead for all practical purposes. 32 per cent of the holdings records showed no receipts for ten years or longer, and $5 \mathrm{I}$ per cent showed no receipts for five years or longer.

The conclusion from this study was to create a new active serial records file to contain only the records for those titles which showed activity within the past five years, thus to concentrate the full effort of the serial assistants on controlling these. The remaining records were left in an inactive file. Thus a well-edited active file could be obtained in approximately one year, whereas revision of the entire file might have required four or more years, for which man hours were not available.

2. Selecting the Card Filing Equipment for the Active Serial Records

Existing serial records were housed in conventional $3 \times 5$ card files which had been located necessarily some distance away from the desks of those who had frequent access to them. A usage study was made covering an entire week by having each person who referred to the file record his use of it. Thus, the principal users of the file were identified. Since users not only had to leave their desks to consult the file, but often found it necessary to withdraw cards for further reference and posting at their desks, many cards were out of file at all times, and the costs of refiling these records were excessive. By locating the active file immediately adjacent to the desk of those having the most constant reference to the records and by substituting open top tub files for enclosed file cabinets much time can be saved and refiling largely eliminated since each card can be returned immediately after posting.

\section{Designing the Order Form}

The single most important form in an acquisition division is the purchase order. Obviously the design of this form should contribute to speed in typing, filing, distribution and receiving. Studies at New York revealed that such factors as the following must be analyzed before an order form is designed:

a. How many titles are ordered at one time from the same source? Six months' experience at NYPL revealed that 46 per cent of all orders called for but one title.

b. In the case of multiple title orders, how frequently are part shipments made by the supplier? At NYPL it was found that part shipments occurred in a high per cent of the cases, thus causing multiple title orders to remain in the open order file for many months.

c. How often must additional typing of cards or manual addition of numbers, 
dates and notations be made after the order form has been typed? These were found to be serious wasters of time under the order form system in use.

Answers to these and related questions led to the conclusion at New York that in most cases a "slip order" form (one title per order) would prove the simplest and most flexible. Also, a carbon inter-leaved snapout form set seemed to afford the greatest speed in preparation and eliminated retyping and manual addition of information. Since a number of copies of each order were required the use of electric typewriters was indicated.

\section{Designing Gift Request and Fol- low-up Letters}

In the year ending June 30 , 1950 the Acquisition Division prepared and mailed over 20,000 letters soliciting samples and gifts or following up delinquent numbers of periodicals. Letter requests were found to be of three types: printed post cards, printed form letters, and individually typed letters. In order to secure a knowledge of the types of requests being made by letter and post card, a study of all pieces issued during one month was conducted.

The most important finding of this study was the need to design request forms which would stimulate and facilitate prompt response. Conventional letters calling for replies are often inconvenient and time-consuming when the recipient must draft those replies. Such requests from libraries seem often to be set aside for later attention when more urgent mail has been attended to. This may result in delay and possibly loss of the request. A more productive request letter would seem to be a letter (not a post card) arranged in three parts:

Part I-Subject: Author, Title, Volume, Number, Date, etc.

Part 2-The request: Succinctly stated and, if possible, indicated by a check mark beside one of a series of multiple choice statements, such as "Please place our name on your com- plimentary mailing list" or "Please help us complete our file" or "Please furnish us a sample copy," etc.

Part 3-The reply: Blank spaces in which the recipient can immediately hand- or typewrite his reply on the request form itself and insert in a return addressed envelope. A preprinted mailing slip provides an additional inducement and convenience.

\section{Strengthening Management Controls}

Organization and procedures are the machinery of administration. But no machine, no matter how well built or how new, can function for long without constant maintenance and lubrication. Factory managers provide a sizable part of their annual overhead budget for plant maintenance. Every careful automobile owner follows a regular regimen of inspection, oil change and lubrication. Administrative machinery requires just such constant attention and periodic adjustment to assure its proper functioning. This is the part which effective controls play in the management of an administrative activity like an acquisition division. Management controls may be defined as those techniques by which supervisors evaluate the performance of their organization and its procedures. The number and types of controls which may be used are dependent upon the size and complexity of the organization and the ingenuity of its managers. Three types of controls which are especially pertinent in the acquisition activity are (I) quality control, (2) cost control, and (3) morale control.

\section{Quality Control}

The promptness and accuracy with which the requirements of each division served are fulfilled by the Acquisition Division may be checked on a qualitative level. A problem in quality control exists when any appreciable number of the divisions served are dissatisfied with the promptness and accuracy of this service. A more serious problem exists when the supervisors of a service division are uninterested in the com- 
plaints of those whom they serve.

Important quality control checks in an Acquisition Division include: I) a constant sound-out of the attitude of those being served to be obtained from frequent direct contacts with the chiefs of divisions served, 2) periodic checks on the length of time in elapsed working days required to process a procurement request, 3) periodic surveys of the number of open orders on file to determine the length of time each has been outstanding, 4) periodic inventories of work on hand at each desk to reveal the volume and age of the backlog, and 5) periodic reviews of the performance of suppliers, showing factors such as the number of titles ordered, the number furnished, the number of substitutions made, the number of follow-up requests which became necessary, the average elapsed time between date of order and date of receipt, promptness in anwering locate and quote requests, cooperation in marking packages, invoices, etc.

\section{Cost Control}

In an administrative organization cost control is concerned primarily with the productivity of personnel and secondarily with expenses for supplies and equipment. This is true since salaries represent 75 per cent or more of total operating costs. There is but one approach to the control of payroll costs-that is, the measurement of work produced from month to month and year to year in relation to the man hours expended. For example, how many orders were written this month, compared to last month, and how many man hours were allocated in each period to accomplish this task.

It is true that precise measurement of office work is difficult and time consuming, but there are many compromises with precision which still provide useful results. As a minimum every acquisition activity should maintain rough statistics to reflect the rela- tive volume of work produced from month to month. Such statistics should be simple, such as number of orders issued, number of letters prepared, number of pieces received, number of invoices passed, etc. Through constant review of such data, an alert supervisor will detect major changes in the work output of his group and determine what steps may be required to maintain economical performance, e.g., by decreasing personnel, rearranging assignments, smoothing out fluctuations in workload, etc.

\section{Morale Control}

There is no gainsaying the fact that quality control and cost control are predominantly dependent upon the attitude, loyalty and enthusiasm of the staff, both individually and as a group. The tests and checks mentioned in connection with quality and cost controls are the mechanical aspects of management control. These are factual, statistical controls for the most part. Development of sustained high morale constitutes a much less concise form of control and represents perhaps the greatest challenge to supervisors in any type of activity. We can, however, isolate a few of the essential ingredients of morale control. These are: I) Equity in job evaluation and salary classification, 2) Preservation and expansion of opportunities for employee development and participation in management improvement, and 3) Comfortable working conditions.

\section{Conclusion}

There are few enterprises, either in libraries or outside of them which will not benefit from continuing attention to the development of greater administrative competence. The techniques by which this competence is achieved are I) sound organization of personnel, 2) maintenance of simple procedures and 3) the development of effective controls. 